ECONOMICS

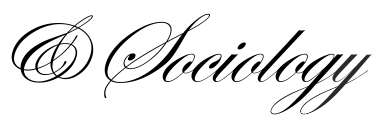

\author{
Małgorzata Bartosik- \\ Purgat, \\ Poznan University of Economics \\ and Business, \\ Poznan, Poland, \\ E-mail:m.purgat@ue.poznan.pl \\ Nela Filimon, \\ Universitat de Girona, \\ Girona, Spain, \\ E-mail: Nela.Filimon@udg.edu
}

Meltem Kiygi-Calli,

Okan University,

Tu₹la-Istanbul, Turkey,

E-mail:

meltem.kiygicalli@okan.edu.tr

Received: July, 2016

1st Revision: November, 2016

Accepted: December, 2016

DOI: $10.14254 / 2071-$

789X.2017/10-1/13

JEL Classification: I23, I25, $\mathrm{J} 1$

Keywords: social media, higher education, international markets.

\section{SOCIAL MEDIA AND HIGHER EDUCATION - AN INTERNATIONAL PERSPECTIVE}

\begin{abstract}
This study explores the use of social media in higher education with a particular focus on the role of cultural and socioeconomic differences. The dataset, built on surveyed respondents from China, Poland, Spain, Turkey and United States, was analysed using quantitative techniques that allowed us to test various hypotheses. Findings show that the use of social media for educational purposes is determined by socio-demographic variables (gender, age, education level) that returned different social media users' profiles across countries. Overall, the results indicate that social media is a useful tool of communication between teachers and students but that national cultural differences must be taken into account in the design of subjects and teaching materials used by teachers in the digital environment. From another point of view, the results related with the cultural differences and the socio-economic determinants may give insight to the marketers in the promotion of education related products such as books, language schools, degree and certificate programs in social media.
\end{abstract}

\title{
Introduction
}

The impact of information and communication technologies (ICTs) can be seen in almost every area of human activity, ranging from entertainment, information searching, decision making-processes, purchasing, and professional issues in education where traditional styles and methods are often replaced with modern ones that are designed to support and facilitate time-saving, effort and costs in everyday routines (Nichols and Anderson, 2005; Skiera et al., 2015). In keeping with this, we focus on the importance of social media (SM) in the field of education (Gammon and White, 2011; Ngai et al., 2015; Richardson, 2006) from the perspective that individuals expand their knowledge to a varying extent.

SM tools enable involvement and cooperation between students and teachers, as well as peers from different parts of the world (Bartow, 2014; Kim et al., 2014). In this respect the increasing usage of SM by both teachers and students has attracted substantial research attention aimed at assessing, for example, their role in higher education (see e.g., Tess, 2013, for a comprehensive overview of the literature); research that has failed to produce clear-cut 
results. Thus, some authors advocate greater use of SM in classrooms because of their capacity to enhance creativity and diversity in teaching styles as a means of fostering active learning for students (Anderson, 2007; Selwyn, 2010); enhancing pedagogical choice for teachers (McLoughlin and Lee, 2010); as a lever for promoting learning in a dynamic and networked social environment (Hung and Yuen, 2010); and as a tool to enhance students' interest, engagement, control and responsibility for their education (Blankenship, 2010, p. 12). Other studies advocate a cautious adoption and usage of SM for educational purposes, stressing the necessity of some a-priory literacy in SM. According to a recent US survey carried out among 1000 college and university faculty members, cited by Blankenship (2010, p. 12), attention, participation, collaboration, network awareness and critical consumption are the five main problems that need to be taken into account in order to ensure an effective and well-informed usage of SM. All in all, there are few comparative studies of the impact of SM on individuals' behaviour, and in particular, on their learning habits.

The main aim of the paper is to identify if the socio-demographic variables (gender, age, education level) influence the use of SM for educational purposes for students from various environments such as China, Poland, Spain, Turkey, and the United States (US). This research topic is both important and pertinent given the increasing international composition of the classrooms (i.e., Erasmus programmes, international masters programmes, etc.). In order to design teaching methods that are adapted to the digital environment it is therefore important for teachers to understand how students' socio-economic and cultural profiles influence their preferences for SM's usage. The theoretical analysis has been based on literary studies and empirical data collected in several countries in order to identify the differences and similarities among them. To collect the data for the exploratory empirical study the authors used two research methods: PAPI (Paper and Pen Personal Interview) and CAWI (Computer Assisted Web Interview).

The structure of this paper is as follows: first, the relevant literature is reviewed. This is followed by a description of the applied methodology. Then the results of the empirical study are presented and discussed. The paper ends with a discussion of the limitations and suggestions for future research.

\section{Literature overview}

Social media is an area of interest and research for many practitioners and researchers studying the influence of these media on different aspects of human life and activity (Merrill, 2011; Patino et al., 2012). Although SM were originally intended to enhance social interactions they soon became a tool that was also used by firms, for example, to build brand loyalty, and by other institutions, such as universities, libraries, etc. (Cassidy et al., 2011). Due to their nature, SM can be successfully used for educational purposes because according to Kaplan and Haenlein (2010, p. 61) they are a set (group) of applications that are technically and ideologically based on the foundations of Web 2.0, which enable the creation and sharing of content among users (Williams et al., 2012). Moreover, although networking is treated as an informal method of communication and information gathering, informal learning can be an essential element in higher education (Kassens-Noor, 2012). According to Hicks and Graber (2010) Web 2.0 tools offer a new form of learning and teaching. In their opinion the research in this field should be further developed with the purpose of providing teachers with new solutions that can enrich their teaching techniques (see also Kassens-Noor, 2012).

Research evidence shows that the most popular SM are the ones that connect people into networks of friends who share common characteristics, for example, Facebook, Instagram or LinkedIn (Duggan et al., 2015). Thus, users can search for people that are able to provide particular information, help them to find it, or transfer knowledge to other people 
(Ray, 2014; Schouten, 2011). Facebook, in particular, is a source that is easily accessible and also simple to use, and is often employed by students to ask questions about studies and to study interactively (Benson et al., 2015; Gregory et al., 2014; Hussain, 2012). Highly popular media are also those that enable Internet users to express themselves on a specific topic in the form of the written word, oral expression, taking and collecting photos or recording videos, for example, Twitter, YouTube, Instagram, Pinterest, and also to use the information placed there by other users (Hamid et al., 2015; Munguatosha et al., 2011; Nakagawa and Arzubiaga, 2014; Schouten, 2011; Ward, 2006).

The popularity of various global SM is culturally differential. Many SM are available in most countries, however in some countries digital communities use local media that are often equivalent versions of the international ones (Ahmed, 2011). This is the case, for example, in China, where Youku is replacing YouTube, and Renren or Qzone are replacing Facebook (Saw et al., 2013; Zhang and Xueb, 2015).

\section{Hypotheses development}

The main research question to be answered here is: what are the determinants of the use of SM for educational purposes? The literature widely presents the results of various projects relating to the use of the Internet in general, and of ways and areas for using SM (Bolton et al., 2013; Hamade, 2013; Lin and Lu, 2011). However, there are few studies directly related to educational purposes (Hamid et al., 2015; Sheldon, 2015) or to the cultural and demographic factors that differentiate this use (Furner and George, 2012). Much of the literature presents studies on the use of SM in higher education from the perspective of the universities (Gammon and White, 2011; Nicholas et al., 2011; Tenopir et al., 2013; Zhang et $a l ., 2014)$, however, it is difficult to find studies that have undertaken empirical research to address the theoretical issues included in this paper. Therefore, this is an attempt to fill this gap. Based on the literature review, observation, and experience, the authors have developed and empirically tested the hypotheses, whose background has been presented in the following paragraphs.

Gender. Gender is often indicated as an important determinant differentiating the use of new ICTs. Recent evidence shows that SM are more often used by women than men (Madden and Zickuhr, 2011; Nadkarni and Hofmann, 2012). Women also spend more time using SM and have more friends on SM (Moore and McElroy, 2012). Ruleman (2012) shows that women are more likely to use the Internet to communicate (via e-mail, SM), as well as for academic purposes, whereas men more often search for information about current events, entertainment, and use the Internet to play games (Jones et al., 2009; Junco et al., 2010; Muscanell and Guadagno, 2012). Thus, based on existing research evidence, the following hypothesis has been formulated: H1. Women use SM for educational purposes to a higher degree than men.

Age. A very large group of SM users belong to the generation of the so-called digital natives (Brenner and Smith, 2013; Prensky, 2001). The report by the Pew Research Center shows that $86 \%$ of SM users are undergraduate students (Smith et al., 2011). This is a group that is said to be different in that it learns in a different way to others, it has different social behaviour and different expectations towards life, and a different level of education. Digital natives are people who prefer to receive information quickly by means of modern technological solutions and methods (ICTs). They also exhibit low tolerance for traditional methods of transmitting knowledge, for example, lectures (Jones et al., 2009). In studies of American youth conducted by Ruleman (2012), it was found that younger students were more likely than their older fellow students to use Facebook and text messages while studying. Considering the features and style of behaviour of digital natives, the following hypothesis 
has been formulated: H2. Younger people (<30 years) more often use SM for educational purposes than do older people.

Education level. Educational level is usually associated with people's age. Students use of SM (like e.g. Twitter) can increase their engagement through interpersonal connections and communication (Kahn et al., 2016). Research evidence shows that undergraduate students are active users of SM, which are used both for academic purposes and for information searching in everyday life (Duggan et al., 2015). Along the same lines, Park (2010) indicates that undergraduate students use SM to a greater extent than post-graduates (PhD students). The research by Head (2013) shows that doctoral students prefer materials available in printed journals and e-journals rather than using SM. Kim, Sin and Tsai (2014) found similar results regarding the use of Wikipedia, that is, a lower level of education was associated with a more frequent use of Wikipedia's sources. Based on the existing evidence the following hypothesis has been formulated: H3. SM are more often used for educational purposes by undergraduates and graduates (Bachelor and Master) than by schoolboys/girls or PhD students.

\section{Method}

Methodologically, this paper takes a deductive and exploratory approach and the aim is to check the accuracy of the hypotheses arising from the literature study The research presented in this paper was conducted in the 2016 in China, Spain, Poland, Turkey, and the United States. The main criteria for building the sample of countries were the local cultural heritage (to assist with identifying the differences or similarities among cultures), and the possibilities for preparing and conducting the test procedure and the fieldwork. Two techniques were used for the data collection: PAPI (paper and pen interview) and electronic forms CAWI (computer assisted web interview). The measurement instrument was a standardized questionnaire prepared for the purpose of this research. The element differentiating the research questionnaire in particular markets was the language. In the preparation of the different versions of the questionnaire a back translation procedure was used in order to eliminate any mistakes stemming from linguistic, lexical or context differences (Craig and Douglas, 2006).

The final dataset gathered information from 1376 respondents, including 295 from China, 296 from Poland, 130 from Spain, 260 from United States, and 395 from Turkey. The data was collected, firstly, by random sampling method, but the response rate was very low (3.5\%), and authors decided to use non-random sampling. Designated research assistants gathered the questionnaires from the respondents in each market. The differences in size between the groups researched and the sampling method that was applied set limitations on the interpretation of the results obtained which, in this case, should not be fully generalized.

\section{Data analysis and Results}

\subsection{Respondents' profiles}

The respondents in each country were people who had agreed to participate and were willing to describe how they use SM for educational purposes. The study participants were distinguished according to three age groups: 15-20 years, 21-30 years, and 31 years or over (Table 1). In China, Poland, and Turkey respondents within the 21-30 age group predominated. This age group was also dominant in Spain. On the other hand, in the United States most participants belonged to the 15-20 years age group. 
Table 1. Respondents' profile (\%)

\begin{tabular}{lccccc}
\hline Determinants & Spain & China & Poland & United States & Turkey \\
\hline Women & \multicolumn{2}{c}{ Gender } & & & \\
\hline Men & 50.8 & 68.1 & 70.9 & 56.5 & 48.7 \\
\hline No data & 49.2 & 31.2 & 27.7 & 43.1 & 49.7 \\
\hline \multicolumn{7}{c}{ Age } & 0.7 & 1.3 & 0.4 & 1.5 \\
\hline 15-20 years & 0.0 & & & \\
\hline 31-30 years & 40.8 & 14.2 & 35.5 & 79.6 & 9.6 \\
\hline 31 years and over & 50.8 & 66.4 & 63.5 & 16.9 & 76.5 \\
\hline Schoolboy/girl/college & 0.0 & 19 & 0.7 & 3.5 & 13.4 \\
\hline Bachelor degree & Education Level & & & \\
\hline Master degree & 0.77 & 17.29 & 4.42 & 33.08 & 5.06 \\
\hline Postgraduate, PhD student & 93.38 & 27.79 & 76.91 & 58.47 & 73.0 \\
\hline & 3.08 & 42.03 & 16.33 & 5.77 & 7.65 \\
\hline
\end{tabular}

Source: own research.

Taking into account the diversity of the dataset, it should be emphasised that it was difficult to determine whether there was a significant dominance of any gender. There was almost gender parity in most of the countries (e.g., Spain, United States, and Turkey). However, women predominated in the Chinese and Polish groups.

In terms of level of education, it should be noted that young people, that is, college students (in the case of the United States) and bachelor and master's students predominated in almost all countries in the dataset. The largest group classified as schoolboy/girl was observed in the United States, which is also related to the structure of this group in terms of age. In Poland, Spain, and Turkey bachelor students were dominant, while master's students formed the largest group in China (see Table 1).

\subsection{Patterns of SM users}

To examine the interdependence between socio-demographic variables such as gender, age, education level, and the use of SM for educational purposes, several indicators of behaviour were calculated and analysed. Thus, respondents were asked to specify the frequency of using various SM (very often, often, from time to time, rarely, very rarely, never) for educational purposes (see Table 2). Based on a pilot questionnaire tested in Poland, the five most often indicated educational activities were: (1) using SM to look for information and materials for study $\left(\mathrm{ED}_{1}\right)$; (2) communicating with students in order to send or receive study materials $\left(\mathrm{ED}_{2}\right)$; (3) communicating with teachers in order to send or receive study materials $\left(\mathrm{ED}_{3}\right)$; (4) communicating with teachers about organisational study issues $\left(\mathrm{ED}_{4}\right)$; and (5) establishing contacts by means of SM in order to learn and practice foreign languages $\left(\mathrm{ED}_{5}\right)$.

For the reliability analysis Cronbach's Alpha was calculated and the value obtained $(\alpha=0.78)$ has confirmed the reliability of the proposed scale (Nunnally, 1978).

Additional measures, such as Cramer's $V$ factor and Pearson's chi-square statistics, were used to determine the strength of the interdependence between the socio-demographic variables in each country and the behavioural patterns emerging from the use of SM.

The results for the Pearson's chi-square statistics and the Cramer's $V$ factor, which are presented in Table 2, show that there are differences between the countries analysed with 
respect to the correlation between the socio-demographic determinants and the use of SM for educational purposes. The significant correlates ( $p$-value $<0.05)$, are discussed below.

Table 2. Correlations between gender, age, education level and the way of using SM for educational purposes

\begin{tabular}{|c|c|c|c|c|c|c|c|c|c|c|}
\hline \multirow{2}{*}{$\begin{array}{l}\text { Sign of } \\
\text { activity }\end{array}$} & \multicolumn{2}{|c|}{ Spain } & \multicolumn{2}{|c|}{ China } & \multicolumn{2}{|c|}{ Poland } & \multicolumn{2}{|c|}{ United States } & \multicolumn{2}{|c|}{ Turkey } \\
\hline & $\chi^{2}$ & $V$ & $\chi^{2}$ & $V$ & $\chi^{2}$ & V & $\chi^{2}$ & V & $x^{2}$ & $V$ \\
\hline \multicolumn{11}{|c|}{ Gender } \\
\hline $\mathrm{ED}_{1}$ & $12.8 *$ & 0.32 & 4.5 & 0.13 & 7.6 & 0.16 & 4.3 & 0.13 & $16.65 * *$ & 0.21 \\
\hline $\mathrm{ED}_{2}$ & 6.2 & 0.21 & 9.35 & 0.18 & $16.5^{* *}$ & 0.24 & 4.8 & 0.13 & 4.2 & 0.1 \\
\hline $\mathrm{ED}_{3}$ & 3.8 & 0.17 & 8.16 & 0.17 & 8.09 & 0.17 & 3.5 & 0.11 & $10.6^{*}$ & 0.17 \\
\hline $\mathrm{ED}_{4}$ & 5.5 & 0.2 & 4.3 & 0.12 & 4.7 & 0.13 & 4.48 & 0.13 & 6.5 & 0.13 \\
\hline $\mathrm{ED}_{5}$ & 6.05 & 0.23 & 9.8 & 0.18 & 9.16 & 0.18 & 8.88 & 0.19 & $17.91 * *$ & 0.22 \\
\hline \multicolumn{11}{|c|}{ Age } \\
\hline $\mathrm{ED}_{1}$ & 4.8 & 0.2 & $41.24 * *$ & 0.27 & 14.3 & 0.16 & 3.7 & 0.08 & 13.36 & 0.13 \\
\hline $\mathrm{ED}_{2}$ & 4.4 & 0.19 & $33.51 * *$ & 0.24 & 11.14 & 0.14 & 7.4 & 0.11 & $60.3^{* *}$ & 0.3 \\
\hline $\mathrm{ED}_{3}$ & 5.87 & 0.22 & $25.6 * *$ & 0.21 & 8.11 & 0.12 & 13.04 & 0.16 & $49.69 * *$ & 0.26 \\
\hline $\mathrm{ED}_{4}$ & 5.27 & 0.21 & $34.45 * *$ & 0.25 & 13.3 & 0.15 & 11.03 & 0.14 & $57.7 * *$ & 0.28 \\
\hline $\mathrm{ED}_{5}$ & $12.95 * *$ & 0.33 & 20.01 & 0.19 & 11.24 & 0.14 & 6.7 & 0.11 & $40.99 * *$ & 0.24 \\
\hline \multicolumn{11}{|c|}{ Education Level } \\
\hline $\mathrm{ED}_{1}$ & 13.65 & 0.19 & $57.43 * *$ & 0.23 & 13.7 & 0.12 & 17.25 & 0.15 & $21.75^{* *}$ & 0.13 \\
\hline $\mathrm{ED}_{2}$ & 14.46 & 0.19 & $72.4 * *$ & 0.25 & 21.16 & 0.15 & 15.17 & 0.14 & $78.8 * *$ & 0.3 \\
\hline $\mathrm{ED}_{3}$ & 9.33 & 0.15 & $64.0 * *$ & 0.24 & 12.2 & 0.11 & $36.7^{*}$ & 0.23 & $49.05 * *$ & 0.26 \\
\hline $\mathrm{ED}_{4}$ & 21.24 & 0.23 & $65.99 * *$ & 0.24 & 11.48 & 0.11 & 23.54 & 0.17 & $57.7 * *$ & 0.28 \\
\hline $\mathrm{ED}_{5}$ & 3.2 & 0.09 & 24.43 & 0.15 & $25.86^{*}$ & 0.17 & 15.71 & 0.14 & $40.99 * *$ & 0.24 \\
\hline
\end{tabular}

$*$ Correlation is significant at the $p<0.05$ level.

** Correlation is significant at the $p<0.01$ level.

$\mathrm{ED}_{1}-\mathrm{ED}_{5}$ - ways of using SM for educational purposes.

Source: own research.

Gender. Analysing the criterion of gender (on the basis of Pearson's chi-square) it should be emphasised that in two groups - China and the United States - no significant interdependence between this variable and using SM for educational purposes $(p>0.05)$ was recorded. In Spain and Poland only one statistically significant correlation $(p<0.05$ and $p<0.01)$ was observed. Thus, in Spain, gender differences are significant in the use of SM, with women using them more often than men to search for information and learning materials $\left(\mathrm{ED}_{1}\right)(p<0.05)$. The strength of this relationship (as indicated by the Cramer's $V$ factor) is at the moderate level $(V=0.32)$. In the Polish group, the correlation $(p<0.01)$ between gender and the $\mathrm{ED}_{2}$ group (the use of SM to exchange study materials with other students) was significant for women, as more frequent users, and the strength was lower than in Spain $(V=0.24)$. Among the Turkish respondents three uses of SM for educational purposes were found to be significant with respect to gender: whereas Turkish women use SM more often than men for $\mathrm{ED}_{1}(p<0.01 ; V=0.21)$, most of the Turkish men prefer to use SM for communication with teachers $\left(\mathrm{ED}_{3} ; p<0.05 ; V=0.17\right)$ and to make international acquaintances in order to learn foreign languages $\left(\mathrm{ED}_{5} ; p<0.01 ; V=0.22\right)$. In China and the United States no significant gender differences were found.

Overall, the results of testing our first hypothesis (H1) are rather heterogeneous, indicating the existence of significant gender differences in European countries (Spain, Poland, Turkey) as compared with China and the US.

Age. The analysis of the correlation between age and the use of SM for educational purposes showed significant interdependencies in two countries - China and Turkey. In China 
age greatly influences the use of $\mathrm{SM}$ in relation to $\mathrm{ED}_{1}(p<0.01 ; V=0.27), \mathrm{ED}_{2}(p<0.01$; $V=0.24), \mathrm{ED}_{3}(p<0.01 ; V=0.21)$, and $\mathrm{ED}_{4} \quad(p<0.01 ; V=0.25)$. All these activities are more often performed by individuals within the 21-30 age group. In the Turkish group, age is a significant variable in differentiating the use of SM in relation to almost all educational purposes (except for $\left.\mathrm{ED}_{1}\right): \mathrm{ED}_{2}(p<0.01 ; V=0.3), \mathrm{ED}_{3}(p<0.01 ; V=0.26), \mathrm{ED}_{4}(p<0.01$; $V=0.28)$, and $\mathrm{ED}_{5}(p<0.01 ; V=0.24)$. As in China, individuals within the $21-30$ age group also predominate. In Spain, age had a significant impact for only one activity, $\mathrm{ED}_{5}(p<0.01$; $V=0.33$ ), and this was for respondents within the 21-30 age group. No significant correlations were found for Poland and the United States, showing that in these two countries the SM users exhibit rather similar behaviour in terms of using $\mathrm{SM}$ for $\mathrm{ED}_{1}, \mathrm{ED}_{2}, \mathrm{ED}_{3}, \mathrm{ED}_{4}$, and $\mathrm{ED}_{5}$, regardless of age. Thus, the validity of the $\mathrm{H} 2$ hypothesis was proved in China, Turkey, and to a lesser extent in Spain. In Poland and the United States age does not differentiate using SM for educational purposes.

Education level. The findings on the significance of education level on the use of SM for educational purposes show similar results to those for age, with significant differences in the Chinese and Turkish groups. In the Chinese group, education differentiates the use of SM in relation to $\mathrm{ED}_{1}(p<0.01 ; V=0.23), \mathrm{ED}_{2}(p<0.01 ; V=0.25), \mathrm{ED}_{3}(p<0.01 ; V=0.24)$, and $\mathrm{ED}_{4}$ $(p<0.01 ; V=0.24)$. The greatest use of SM for educational purposes was observed among the Chinese master's students. In the Turkish group, bachelor students exhibit significantly different behaviour when it comes to the use of SM for all of the five educational purposes considered here: $\mathrm{ED}_{1}(p<0.01 ; V=0.13), \mathrm{ED}_{2}(p<0.01 ; V=0.3), \mathrm{ED}_{3}(p<0.01 ; V=0.26), \mathrm{ED}_{4}$ $(p<0.01 ; V=0.28)$, and $\mathrm{ED}_{5}(p<0.01 ; V=0.24)$. In Poland, education level was significant in the use of SM for ED5 $(p<0.05 ; V=0.17)$, and in the US for $\mathrm{ED}_{3}(p<0.01 ; V=0.23)$. In both cases bachelor students dominate as far as these behaviours are concerned. In the Spanish group all users of SM behave similarly in their use of SM for educational purposes, regardless of education level. Therefore, the validity of the H3 hypothesis was proved in relation to the Chinese and Turkish groups and, to a lesser extent, the Polish and American groups.

\section{Discussion and Conclusions}

This exploratory analysis was intended to address some existing gaps in the area of SM use for educational purposes from a comparative international perspective. The results show that national cultural differences exist in the use of SM for educational purposes. Although the lack of a random sampling procedure in the selection of the respondents imposes some limitations on the generalisation of the results, it is worthwhile noting that a significant number of studies in the field, where the observation unit is the pupil/student, rely on ad-hoc data collected from students (Jones et al., 2009; Ruleman, 2012; Smith et al., 2011).

The use of ICTs (SM in this case) seems to depend on socio-demographic variables such as gender, age and education level, each of which impacts differently in the countries analysed. All in all, the findings indicate that, in the digital environment, cultural differences must be taken into account in the design of subjects and teaching materials used by teachers. With the exception of Turkey, our results confirm existing evidence in respect of gender (see e.g., Ruleman (2012) and Muscanell and Guadagno (2012) who show that women use SM for educational purposes much more than men). In the case of Turkey, men use SM more often than women for two educational activities, $\mathrm{ED}_{3}$ and $\mathrm{ED}_{5}$.

Regarding the influence of generational differences (age groups), the research evidence is rather scarce. Ruleman (2012) used the example of Facebook to show that younger American students used more SM while studying than did their older colleagues. Our results add to the existing evidence by showing that in Turkey and China there is a significant 
relationship between age and the use of SM for educational purposes for respondents within the 21-30 age group. The results show that SM should mainly be used as communication tools for educational purposes by university teachers (not teachers in primary or secondary schools). Furthermore, education level seems to have the strongest impact on SM usage for educational purposes. Existing literature shows that it is mostly undergraduate students (bachelor level) that communicate with other students, university teachers, etc. by means of SM tools (Duggan et al., 2015; Head, 2013; Kim et al., 2014). Our results indicate that the strongest dependences between education level and SM use for academic purposes was observed in Turkey and China, with the Chinese master's students and the Turkish bachelor students as the dominant SM users for all educational purposes. These findings could be particularly useful for tailoring specific classes for students from these cultural environments. From a marketing point of view, these results may be taken into account in the promotion of education related products. Cultural differences and socio-demographic determinants of the use of SM for educational purposes may give insight to the marketers in the promotion of education related products such as books, language schools, degree and certificate programs.

Overall, SM appear to be useful tools in the communication between teachers and students and this research shows the various alternatives offered by the application of the ICTs (SM) in the educational field. These results provide a first indication about where (in which markets) this process has already taken place and where new instruments, such as web sites and digital applications, should be developed (e.g., China and Turkey). In the markets where, according to our findings, SM are not used for educational purposes, digital marketers could consider launching information campaigns to show the capabilities of SM in these areas. Future research could expand the analysis to the use of other social media for educational purposes, such as Facebook.

\section{Limitations}

Conducting empirical studies and using primary research methods is almost always associated with certain limitations and their number increases when conducting international research. The way of choosing the respondents from the researched population and the sample size constitutes important and, at the same time, critical decisions in such studies. Due to various aspects (most of all financial) non-random sampling was applied in this study. The consequence of this is the lack of possibilities to apply the results to the whole of the researched population. But, the research limitations are very often a stimulus to either continue the study or expand it, especially in relation to international activities. Further research could expand the utility of SM in random and bigger samples.

\section{References}

Ahmed, M. A. (2011), Social media for higher education in developing countries - An intercultural perspective, Educating Educators with Social Media, Vol. 1, pp. 59-80.

Anderson, P. (2007), What is Web 2.0?: Ideas, technologies and implications for education, JISC Technology \& Standards Watch (February), Vol. 1, No. 1, pp. 1-64.

Bartow, S. M. (2014), Teaching with social media: disrupting present day public education, Educational Studies, Vol. 50, pp. 36-64.

Benson, V., Saridakis, G. and Tennakoon, H. (2015), Purpose of social networking use and victimisation: Are there any differences between university students and those not in HE? Computers in Human Behavior, No. 51 (Part B, October), pp. 867-872.

Blankenship, M. (2010), How social media can and should impact higher education, Hispanic Outlook in Higher Education Magazine, 21 (November 29, 2010), pp. 11-12, 
http://www.hispanicoutlook.com/mark-blankenship/?tag=01\%2F03\%2F2011+Issue (10 October 2016).

Bolton, R. N., Parasuraman, A., Hoefnagels, A., Migchels, N., Kabadayi, S., Gruber, T., Komarova Loureiro, Y. and Solnet, D. (2013), Understanding Generation Y and their use of social media: a review and research agenda, Journal of Service Management, Vol. 24, No. 3, pp. 245-267.

Brenner, J., and Smith, A. (2013), 72\% of online adults are social networking site users, Pew Research Center, http://www.pewinternet.org/ /media/Files/Reports/2013/PIP_Social_networking_sites_ update.pdf (21 November 2016).

Cassidy, E. D., Britsch, J., Griffin, G., Manolovitz, T., Shen, L. and Turney, L. (2011), Higher education and emerging technologies: student usage, preferences and lessons for library services, Reference \& User Services Quarterly, Vol. 50, No. 4, pp. 380-391.

Craig, C. S. and Douglas, S. P. (2005), International Marketing Research, $3^{\text {rd }}$ Edition, Chichester: John Wiley\&Sons, Ltd.

Duggan, M., Ellison, N. B., Lampe, C., Lenhart, A. and Madden, M. (2015), Social media update 2014, http://www.pewinternet.org/files/2015/01/PI_SocialMediaUpdate20144.pdf (10 November 2016).

Furner, C. P. and George, J. F. (2012), Cultural determinants of media choice for deception, Computers in Human Behavior, Vol. 28, No. 4, pp. 1427-1438.

Gammon, M. A. and White, J. (2011), (Social) media literacy: challenges and opportunities for higher education, In: C. Wankel (Ed.), Educating Educators with Social Media (Cutting-edge Technologies in Higher Education, Vol. 1, pp. 329-345), UK: Emerald Group Publishing Limited.

Gregory, P., Gregory, K. and Eddy, E. (2014), The instructional network: using Facebook to enhance undergraduate mathematics instruction, Journal of Computers in Mathematics and Science Teaching, Vol. 33, No. 1, pp. 5-26.

Hamade, S. N. (2013), Perception and use of social networking sites among university students, Library Review, Vol. 62, No. 6/7, pp. 388-397.

Hamid, S., Waycott, J., Kurnia, S. and Chang, S. (2015), Understanding students' perceptions of the benefits of online social networking use for teaching and learning, The Internet and Higher Education, Vol. 26, pp. 1-9.

Head, A. J. (2013), Learning the ropes: how freshmen conduct course research once they enter college, Project Information Literacy Research Report, http://projectinfolit.org/pdfs/PIL_2013_FreshmenStudy_FullReport.pdf (10 November 2016).

Hicks, A. and Graber, A. (2010), Shifting paradigms: Teaching, learning and Web 2.0, Reference Services Review, Vol. 38, No. 4, pp. 621-33.

Hung, H. T. and Yuen, S. C. Y. (2010), Educational use of social networking technology in higher education, Teaching in Higher Education, Vol. 15, No. 6, pp. 703-714.

Hussain, I. (2012), A study to evaluate the social media trends among university students, Procedia - Social and Behavioral Sciences, No. 64, pp. 639-645.

Jones, S. Johnson-Yale, C., Millermaier, S. and Pérez, F. S. (2009), U.S. college students' Internet use: race, gender and digital divides, Journal of Computer-Mediated Communication, No. 14, pp. 244-264.

Junco, R., Merson, D. and Salter, D. W. (2010), The effect of gender, ethnicity, and income on college students' use of communication technologies, Cyberpsychology, Behavior and Social Networking, Vol. 13, No. 6, pp. 619-27. 
Kahn, P., Everington, L., Kelm, K., Reid, I. and Watkins, F. (2016), Understanding student engagement in online learning environments: the role of reflexivity, Educational Technology Research and Development, DOI 10.1007/s11423-016-9484-z.

Kaplan, A. M. and Haenlein, M. (2010), Users of the world, unite! The challenges and opportunities of social media, Business Horizons, No. 53, pp. 59-68.

Kassens-Noor, E. (2012), Twitter as a teaching practice to enhance active and informal learning in higher education: The case of sustainable tweets, Active Learning in Higher Education, Vol. 13, No. 1, pp. 9-21.

Kim, K-S., Sin, S-C.J. and Tsai, T-I. (2014), Individual differences in social media use for information seeking, The Journal of Academic Libriarianship, No. 40, pp. 171-178.

Lin, K. Y. and Lu, H. P. (2011), Why people use social networking sites: an empirical study integrating network externalities and motivation theory, Computers in Human Behavior, Vol. 27, No. 3, pp. 1152-1161.

Madden, M. and Zickuhr, K. (2011), 65\% of online adults use social networking sites. http://www.pewinternet.org/media/files/reports/2011/pip-sns-update-2011.pdf (5 November 2016).

McLoughlin, C. and Lee, M. J. W. (2010), Personalized and self-regulated learning in the web 2.0 era: International exemplars of innovative pedagogy using social software, Australasian Journal of Educational Technology, Vol. 26, No. 1, pp. 28-43.

Merrill, N. (2011), Social media for social research: applications for higher education communications, In: Wankel, C. \& Wankel, L. (Eds.), Higher Education Administration with Social Media, Cutting Edge Technologies in Higher Education, Vol. 2, pp. 25-48, Emerald Group Publishing.

Moore, K. and McElroy, J. C. (2012), The influence of personality on Facebook usage, wall postings, and regret, Computers in Human Behavior, Vol. 28, No. 1, pp. 267-274.

Munguatosha, G. M., Muyinda, P. B. and Lubega, J. T. (2011), A social networked learning adoption model for higher education institutions in developing countries, On the Horizon, Vol. 19, No. 4, pp. 307-320.

Muscanell, N. L. and Guadagno, R. E. (2012), Make new friends or keep the old: gender and personality differences in social networking use, Computers in Human Behavior, No. 28, pp. 107-12.

Nadkarni, A., \& Hofmann, S. G. (2012), Why do people use Facebook? Personality and Individual Differences, 52 (3), pp. 243-249.

Nakagawa, K. and Arzubiaga, A. E. (2014), The use of social media in teaching race, Adult Learning, Vol. 25, No. 3, pp. 103-110.

Ngai, E. W. T., Moon, K. K., Lam, S. S., Chin, E. S. K. and Tao, S. S. C. (2015), Social media models, technologies, and applications, Industrial Management \& Data Systems, Vol. 115, No. 5, pp. 769-802.

Nicholas, D., Watkinson, A., Rowlands, I. and Jubb, M. (2011), Social media, academic research and the role of university libraries, Journal of Academic Librarianship, Vol. 37, No. 5, pp. 373-375.

Nichols, M. and Anderson, B. (2005), Strategic e-learning implementation, Journal of Educational Technology and Society, Vol. 8, No. 4, pp. 1-8.

Nunnally, J. C. (1978), Psychometric Theory, 2nd Edition, New York, McGraw-Hill.

Park, J. H. (2010), Differences among university students and faculties in social networking site perception and use: Implications for academic library services, Electronic Library, Vol. 28, No. 3, pp. 417-431.

Patino, A., Pitta, D. A. and Quinones, R. (2012), Social media's emerging importance in market research, Journal of Consumer Marketing, Vol. 29, No. 3, pp. 233-237.

Prensky, M. (2001), Digital natives, digital immigrants, On the Horizon, Vol. 9, No. 5, pp. 1-6. 
Ray, D. (2014), Overcoming cross-cultural barriers to knowledge management using social media, Journal of Enterprise Information Management, Vol. 27, No. 1, pp. 45-55.

Richardson, W. (2006), Blogs, Wikis, Podcasts, and other Powerful Web Tools for Classrooms, Thousand Oaks, CA: Corwin Press.

Ruleman, A. B. (2012), Social media at the university: a demographic comparison, New Library World, Vol. 113, No. 7/8, pp. 316-332.

Saw, G., Abbott, W., Donaghey, J. and McDonald, C. (2013), Social media for international students - it's not all about Facebook, Library Management, Vol. 34, No. 3, pp. 156174.

Schouten, P. (2011), Using social media in study abroad, In: Wankel, L. \& Wankel, C. (Eds.), Higher Education Administration with Social Media, Cutting-edge Technologies in Higher Education, Vol. 2, pp. 127-145, Emerald Group Publishing Limited.

Selwyn, N. (2010), Looking beyond learning: Notes towards the critical study of educational technology, Journal of Computer Assisted Learning, Vol. 26, No. 1, pp. 65-73.

Sheldon, P. (2015), Understanding students' reasons and gender differences in adding faculty as Facebook friends, Computers in Human Behavior, No. 53, pp. 58-62.

Skiera, B., Hinz, O. and Spann, M. (2015), Social media and academic performance: does the intensity of Facebook activity relate to good grades? Schmalenbach Business Review, Vol. 67, No. 1, pp. 54-72.

Smith, A., Rainie, L. and Zickuhr, K. (2011), College students and technology. Pew Research Center, http://pewinternet.org/Reports/2011/College-students-and-technology/Report.aspx. (9 December 2016).

Tenopir, C., Volentine, R. and King, D. W. (2013), Social media and scholarly reading, Online Information Review, Vol. 37, No. 2, pp. 193-216.

Tess, P. A. (2013), The role of social media in higher education classes (real and virtual) - A literature review, Computers in Human Behavior, No. 29, A60-A68.

Ward, R. (2006), Blogs and wikis: A personal journey, Business Information Review, Vol. 23, No. 4, pp. 235-240.

Williams, D. L., Crittenden, V. L., Keo, T. and McCarty, P. (2012), The use of social media: an exploratory study of uses among digital natives, Journal of Public Affairs, Vol. 12, No. 2, pp. 127-136.

Zhang, X., Liu, L., de Pablos, P. O. and She J. (2014), The auxiliary role of information technology in teaching: Enhancing programming course using alice, International Journal of Engineering Education, Vol. 30, No. 3, pp. 560-565.

Zhang, Z. and Xueb, Y. (2015), An investigation of how Chinese university students use social software for learning purposes, Procedia - Social and Behavioral Sciences, No. 186 , pp. $70-78$. 